\title{
Assessment of Antibacterial Property of Mineral Trioxide Aggregate with Chlorhexidine
}

\author{
Shivani.N ${ }^{1}$, Anjaneyulu K² and Muralidharan N. P3 \\ ${ }^{1}$ Saveetha Dental College, Saveetha Institute of Medical and Technical Sciences, \\ Saveetha University, Chennai 600 077, India \\ ${ }^{2}$ Reader, Department of Conservative Dentistry and Endodontics, Saveetha Dental College and \\ Hospitals, Saveetha Institute Of Medical and Technical Sciences, Saveetha University, \\ Chennai 600 077, india \\ ${ }^{3}$ Professor, Department of Microbiology, Saveetha Dental College and Hospitals, Saveetha \\ Institute of Medical and Technical Sciences, Saveetha University, Chennai 600 077, India
}

\section{ABSTRACT}

Infected root canals contain a variety of microorganisms which include aerobes, anaerobes, and fungus. Root canal teeth are more likely to harbor E. faecalis than primary cases. Mineral Trioxide Aggregate is an endodontic repair material which possesses several advantageous properties such as good sealing property, biocompatibility, and antibacterial property. Chlorhexidine is a broad-spectrum antibacterial agent that has shown its effectiveness on various microbes particularly E. faecalis and C. albicans. The aim of this study is to compare and assess the antibacterial property of MTA when mixed with water and Chlorhexidine respectively. The test materials were divided into 2 groups namely group 1. MTA with MTA liquid and group 2. MTA with chlorhexidine. These materials were placed in wells on tryptone soya agar using the Well diffusion method on E. faecalis strain. The agar was incubated at $37^{\circ} \mathrm{C}$ for 24 hours and the zone of inhibition was recorded. Independent sample t test was used to compare the zone of inhibition of the materials being tested. It was found that the zone of inhibition of MTA with distilled water was higher than that of MTA with chlorhexidine. (independent $t$ test, $p<0.05$, statistical significance). From the study, it was found that MTA with MTA liquid (distilled water) had better antibacterial properties than MTA with chlorhexidine

\section{KEY WORDS: ANTIBACTERIAL, MTA, E.FAECALIS, CHLORHEXIDINE, ENDODONTIC THERAPY.}

\section{INTRODUCTION}

Pulpal inflammation also called pulpitis is mainly caused by an opportunistic infection of the pulpal space with oral microorganisms. (Rechenberg, Galicia

\section{ARTICLE INFORMATION}

*Corresponding Author: kanjeneyulu.sdc@saveetha.com Received 18th June 2020 Accepted after revision 7th August 2020 Print ISSN: 0974-6455 Online ISSN: 2321-4007 CODEN: BBRCBA

Thomson Reuters ISI Web of Science Clarivate Analytics USA and Crossref Indexed Journal

\section{Clarivate
Analytics}

NAAS Journal Score 2020 (4.31) SJIF: 2020 (7.728)

A Society of Science and Nature Publication,

Bhopal India 2020. All rights reserved.

Online Contents Available at: http//www.bbrc.in/

Doi: http://dx.doi.org/10.21786/bbrc/13.7/68 and Peters, 2016) The most common path of entry for microorganisms is dental caries. (Bergenholtz, 1981; Hahn, Falkler and Minah, 1991) Other potential pathways for pulpal microbial infection include trauma, cracks, exposed dentinal tubules, or the main apical foramen (Bergenholtz, 1981).

The aim of endodontic treatment is thorough debridement and cleaning of the root canal of an infected pulp tissue so that the canal space can be shaped and prepared to be filled with an inert material thus preventing or minimizing any chances of reinfection (Tabassum and Khan, 2016). The Ideal inert materials for sealing rootend cavities should prevent leakage, have dimensional stability, adhere to the cavity walls, resist resorption, 
and should be moisture resistant; they should also be nontoxic and biocompatible to promote healing (Gartner and Dorn, 1992; Torabinejad, Smith, et al., 1995; Anjaneyulu and Nivedhitha, 2014). However, even after these chemomechanical procedures are performed, bacteria might still be found inside the dentinal tubules with the potential for the disease to persist or emerge leading to endodontic failures (Orstavik, 1981).Failure after endodontic therapy is due to persistent or secondary infection especially of Enterococcus faecalis in poorly and in well-treated root canals (Siqueira, 2001). Hence, apart from the other properties, the inert material which is used to seal the canal must provide some antibacterial property (Torabinejad, Hong, Pitt Ford, et al., 1995; Kayaoglu et al., 2005).

Mineral trioxide aggregate (MTA), which was introduced in 1993 by Mahmoud Torabinejad, have been examined since 1995 as potential antibacterial material (Torabinejad, Hong, McDonald, et al., 1995; Torabinejad, Hong, Pitt Ford, et al., 1995). MTA is a powder consisting of fine hydrophilic particles that in the presence of water forms a colloidal gel that solidifies to form hard cement within approximately $4 \mathrm{~h}$ (Torabinejad, Hong, McDonald, et al., 1995). According to recent studies, MTA is a biocompatible dental material and it was suggested that these biological properties may be due to its excellent sealing ability $(\mathrm{Wu}$, Kontakiotis and Wesselink, 1998), high alkalinity(Tziafas et al., 2002), induction of hard tissue formation(Zhu et al., 2000), and antibacterial effects(Torabinejad, Hong, Pitt Ford, et al., 1995). Because of its physical and chemical properties, the use of MTA as a biomaterial for a wide variety of endodontic treatments has been recommended (Torabinejad and Chivian, 1999).

Chlorhexidine (CHX) initially was used as a general disinfectant because of its broad antibacterial action (Birch and Melville, 1961; Grossman, 1972). It was later shown to inhibit dental caries and reduce the formation of dental plaque. In the early 1960s, chlorhexidine was introduced as an endodontic irrigant and has since been reported as effective in vitro against $E$. faecalis (Siqueira et al., 2002). It is clear that more uses for chlorhexidine in endodontics are being developed with the purpose of improving prognosis by enhancing the antimicrobial properties of endodontic materials. (Stowe et al., 2004) Because chlorhexidine has been incorporated into other dental products with some success, this study aims to assess the antibacterial property of MTA when mixed with Chlorhexidine.

We have numerous highly cited publications on well designed clinical trials and lab studies (Govindaraju, Neelakantan and Gutmann, 2017; Azeem and Sureshbabu, 2018; Jenarthanan and Subbarao, 2018; Manohar and Sharma, 2018; Nandakumar and Nasim, 2018; Teja, Ramesh and Priya, 2018; Janani and Sandhya, 2019; Khandelwal and Palanivelu, 2019; Malli Sureshbabu et al., 2019; Poorni, Srinivasan and Nivedhitha, 2019; Rajakeerthi and Ms, 2019; Rajendran et al., 2019; Ramarao and Sathyanarayanan, 2019; Siddique and
Nivedhitha, 2019; Siddique et al., 2019; Siddique, Nivedhitha and Jacob, 2019). This has provided the right platforms for us to pursue the current study. Our aim is to asses the antibacterial property of MTA when mixed with Chlorhexidine.

\section{MATERIAL AND METHODS}

In this study, we had compared 2 groups as follows: group 1: MTA with distilled water and group 2: MTA with 2\% Chlorhexidine. ( Vishal apiseal MTA and hexidine mouth wash). The study was conducted on double-layered plates, in which the base layer was made of tryptone soya agar which was poured in sterilized Petri plates. A total number of 5 plates were employed. A sterile swab was used to inoculate $E$. faecalis on the surface of the agar to achieve a lawn of growth. The strains were obtained from the Department of Microbiology, Saveetha Dental College, and Hospital. Two uniform wells $(4 \mathrm{~mm}$ diameter, one for each test material) were punched at equidistant points in agar by means of a sterile copper coil after 24 hours. MTA was mixed with a sterile glass slab using sterile spatula according to the manufacturer's instructions by using $1 \mathrm{~g}$ of powder for every $0.35 \mathrm{ml}$ sterile water.

The CHX groups were mixed exactly the same way, substituting 2\% CHX liquid The cavities were filled immediately by materials after being mixed. The plates were then incubated for 24 hours at 37C after which the Zone Of Inhibition was checked. All assays were carried out under aseptic conditions. The diameter of bacterial growth inhibition zones was measured using a millimeter scale with an accuracy of $0.5 \mathrm{~mm}$ in two perpendicular scales for all the samples respectively by an independent observer. The independent sample t test was used to compare the mean Zone Of Inhibition among the materials tested. Statistically significant differences among the groups were set at $\mathrm{p}<0.05$.

\section{RESULTS AND DISCUSSION}

The Zone of Inhibition of MTA with MTA liquid was found to be higher than that of MTA with Chlorhexidine. The mean zone of inhibition of MTA with MTA liquid was found to be $25 \mathrm{~mm}$ and that of MTA with Chlorhexidine was found to be $21.8 \mathrm{~mm}$. (figure 1) MTA with distilled water has statistically higher Zone Of Inhibition when compared to MTA with Chlorhexidine. ( $p<0.05$, statistically significant) ( table 1 and 2). In the current study the microorganism E.faecalis particularly was used because it is the most frequently isolated microorganism recovered from failed endodontically treated cases. The prevalence of $E$. faecalis in root canals was ranging from about 24\% to 77\%. (Baumgartner and Falkler, 1991; Vineet and Nayak, 2016)It possesses several virulence factors that contribute to its ability to survive the effects of conventional root canal therapy.(Chavez De Paz et al., 2003; Bhardwaj, 2013) Hence, when a conventional Root canal treatment fails the need for surgical intervention comes into limelight. 
The agar diffusion method was employed in the current study as it is one of the most employed techniques for testing and assessing the antimicrobial property of materials. This technique has a few limitations. It does not distinguish between bacteriostatic and bactericidal effects of the materials and Zones Of Inhibition is not only related to the inhibitory effects of the material, but also depend on the diffusibility of the material across the medium(Leonardo et al., 2000; Asgary, Akbari Kamrani and Taheri, 2007; Tanomaru-Filho et al., 2007). Also, factors like incubation time,inoculum size, and good agar material also may interfere with the results. However, if most of these factors are handled properly, harmonious and homogenous results may be obtained. Hence, various materials can be compared for their antibacterial effects under similar and favourable test environments. (Tobias, 1988)

Table 1. This table represents the Zone of Inhibition of MTA with Distilled water and MTA with Chlorhexidine

\begin{tabular}{|l|l|l|}
\hline & MTA with Distilled water & MTA with Chlorhexidine \\
\hline Sample 1 & $24 \mathrm{~mm}$ & $21 \mathrm{~mm}$ \\
\hline Sample 2 & $26 \mathrm{~mm}$ & $22 \mathrm{~mm}$ \\
\hline Sample 3 & $27 \mathrm{~mm}$ & $21 \mathrm{~mm}$ \\
\hline Sample 4 & $24 \mathrm{~mm}$ & $22 \mathrm{~mm}$ \\
\hline Sample 5 & $24 \mathrm{~mm}$ & $23 \mathrm{~mm}$ \\
\hline
\end{tabular}

In the current study, the Zone Of Inhibition of MTA with distilled water was found to be slightly higher than that of MTA with Chlorhexidine. A few studies have been done which replaced MTA liquid with Chlorhexidine to mix with MTA powder in order to enhance its antimicrobial activity. From the reports, it was suggested that MTA when mixed with Chlorhexidine produced greater Zone Of Inhibition than MTA when mixed with MTA liquid(Stowe et al., 2004; Bidar et al., 2012). Another study stated that the antimicrobial activity of MTA is improved with incorporation of silver nanoparticles. (Samiei et al., 2013)

It is known that the antimicrobial activity of MTA is attributed to its elevated $\mathrm{pH}$ values. Initially when mixed, the $\mathrm{pH}$ of MTA is 10.2 which rises to 12.5 in 3 hours. It is noted that $\mathrm{pH}$ levels of approximately 12 could terminate the growth of the majority of microorganisms, including E. faecalis.(Silva et al., 2014) Also, the antifungal effect of MTA might also be attributed to its high $\mathrm{pH}$ or to substances that are released from MTA into the media. (Al-Nazhan and Al-Judai, 2003)

In the current study, MTA had an inhibitory effect against $E$ faecalis. Another study reported that MTA did not possess any inhibitory effects against $E$.faecalis. This difference might be because of varied differences in the studies. In the present study, wells were made in the agar in which the test material was condensed allowing an exact amount of MTA per sample and the surface area through which the material could diffuse

Table 2. Showing the Independent sample t test for the Zone of Inhibition of MTA with Distilled Water and MTA with Chlorhexidine. From the table it is evident that MTA with distilled water has statistically higher Zone Of Inhibition when compared to MTA with Chlorhexidine. ( $p<0.05$, statistically significant)

\begin{tabular}{|c|c|c|c|c|c|c|c|}
\hline \multirow{2}{*}{$\begin{array}{l}\text { MTA mixed with } \\
\text { distilled water/ } \\
\text { Chlorhexidine }\end{array}$} & \multirow{2}{*}{$\begin{array}{l}\begin{array}{c}\text { Levine's Test } \\
\text { for Equality } \\
\text { For Variances }\end{array} \\
\text { F }\end{array}$} & \multicolumn{6}{|c|}{$\mathrm{T}$ test for equality of means } \\
\hline & & Sig & $\mathrm{t}$ & df & Sig. (2 tailed) & $\begin{array}{c}\text { Mean } \\
\text { difference }\end{array}$ & $\begin{array}{l}\text { STD. Error } \\
\text { difference }\end{array}$ \\
\hline Equal variance Assumed & 0.144 & 0.714 & -4.824 & 8 & 0.001 & -3.200 & 0.663 \\
\hline Equal variance not Assumed & & & -4.824 & 7.066 & 0.002 & -3.200 & 0.663 \\
\hline
\end{tabular}

Figure 1: showing the mean Zone Of Inhibition of MTA with Distilled Water (Blue) and MTA with Chlorhexidine (Green) from the graph it is evident that MTA with Distilled Water showed a higher Zone Of Inhibition than MTA with Chlorhexidine. $(p<0.05$, statistically significant)

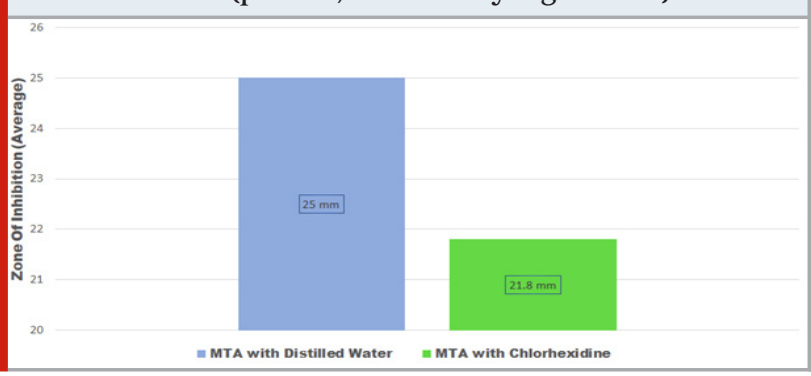

could be increased. In the comparison study, the materials were placed directly on the surface of the agar before incubation. Other differences might be the varied formulations of MTA which are used.

A few studies state that enhancing the antibacterial property of MTA by adding various liquids might adversely affect properties like the compressive strength and biocompatibility of the material.(Holt et al., 2007) However, further studies are necessary to evaluate the properties of this mixture.

\section{CONCLUSION}

Based on the findings of the study, MTA with distilled 
water showed statistically higher Zone Of Inhibition against E.faecalis when compared to MTA with Chlorhexidine. Hence, it is seen that MTA possessed better antibacterial properties against E. faecalis with distilled water than with Chlorhexidine.

\section{ACKNOWLEDGEMENTS}

The authors would like to acknowledge the help and support rendered by the Department of Conservative Dentistry and Endodontics and Microbiology of Saveetha Dental College and Hospitals.

Conflict of Interest: None declared.

\section{REFERENCES}

Al-Nazhan, S. and Al-Judai, A. (2003) 'Evaluation of antifungal activity of mineral trioxide aggregate', Journal of endodontia, 29(12), pp. 826-827.

Anjaneyulu, K. and Nivedhitha, M. S. (2014) 'Influence of calcium hydroxide on the post-treatment pain in Endodontics: A systematic review', Journal of conservative dentistry: JCD, 17(3), pp. 200-207.

Asgary, S., Akbari Kamrani, F. and Taheri, S. (2007) 'Evaluation of antimicrobial effect of MTA, calcium hydroxide, and CEM cement', Iranian endodontic journal, 2(3), pp. 105-109.

Azeem, R. A. and Sureshbabu, N. M. (2018) 'Clinical performance of direct versus indirect composite restorations in posterior teeth: A systematic review', Journal of conservative dentistry: JCD, 21(1), pp. 2-9. Baumgartner, J. C. and Falkler, W. A., Jr (1991) 'Bacteria in the apical $5 \mathrm{~mm}$ of infected root canals', Journal of endodontia, 17(8), pp. 380-383.

Bergenholtz, G. (1981) 'Inflammatory response of the dental pulp to bacterial irritation', Journal of endodontia, 7(3), pp. 100-104.

Bhardwaj, S. B. (2013) 'Role of Enterococci faecalis in failure of Endodontic treatment', Int J Curr Microbiol App Sci, 2(8), pp. 272-277.

Bidar, M. et al. (2012) 'The effects of different concentrations of chlorhexidine gluconate on the antimicrobial properties of mineral trioxide aggregate and calcium enrich mixture', Dental research journal, 9(4), pp. 466-471.

Birch, R. H. and Melville, T. H. (1961) 'Preliminary sterilization of the endodontic field. Comparison of antiseptics', British dental journal, 111, pp. 362-363. Chavez De Paz, L. E. et al. (2003) 'Bacteria recovered from teeth with apical periodontitis after antimicrobial endodontic treatment', International endodontic journal. Wiley Online Library, 36(7), pp. 500-508.

Gartner, A. H. and Dorn, S. 0. (1992) 'Advances in endodontic surgery', Dental clinics of North America, 36(2), pp. 357-378.

Govindaraju, L., Neelakantan, P. and Gutmann, J. L. (2017) 'Effect of root canal irrigating solutions on the compressive strength of tricalcium silicate cements',
Clinical oral investigations, 21(2), pp. 567-571. Grossman, L. I. (1972) 'Sterilization of infected root canals', Journal of the American Dental Association , 85(4), pp. 900-905.

Hahn, C. L., Falkler, W. A., Jr and Minah, G. E. (1991) 'Microbiological studies of carious dentine from human teeth with irreversible pulpitis', Archives of oral biology, 36(2), pp. 147-153.

Holt, D. et al. (2007) 'The Anti-microbial Effect Against Enterococcus faecalis and the Compressive Strength of Two Types of Mineral Trioxide Aggregate Mixed With Sterile Water or 2\% Chlorhexidine Liquid', Journal of Endodontics, pp. 844-847. doi: 10.1016/j. joen.2007.04.006.

Janani, K. and Sandhya, R. (2019) 'A survey on skills for cone beam computed tomography interpretation among endodontists for endodontic treatment procedure', Indian journal of dental research: official publication of Indian Society for Dental Research, 30(6), pp. 834-838.

Jenarthanan, S. and Subbarao, C. (2018) 'Comparative evaluation of the efficacy of diclofenac sodium administered using different delivery routes in the management of endodontic pain: A randomized controlled clinical trial', Journal of conservative dentistry: JCD, 21(3), pp. 297-301.

Kayaoglu, G. et al. (2005) 'Short-term antibacterial activity of root canal sealers towards Enterococcus faecalis', International endodontic journal, 38(7), pp. 483-488.

Khandelwal, A. and Palanivelu, A. (2019) 'Correlation Between Dental Caries And Salivary Albumin In Adult Population In Chennai: An In Vivo Study', Brazilian Dental Science, 22(2), pp. 228-233.

Leonardo, M. R. et al. (2000) 'In vitro evaluation of antimicrobial activity of sealers and pastes used in endodontics', Journal of endodontia, 26(7), pp. 391394.

Malli Sureshbabu, N. et al. (2019) 'Concentrated Growth Factors as an Ingenious Biomaterial in Regeneration of Bony Defects after Periapical Surgery: A Report of Two Cases', Case reports in dentistry, 2019, p. 7046203.

Manohar, M. P. and Sharma, S. (2018) 'A survey of the knowledge, attitude, and awareness about the principal choice of intracanal medicaments among the general dental practitioners and nonendodontic specialists', Indian journal of dental research: official publication of Indian Society for Dental Research, 29(6), pp. 716-720.

Nandakumar, M. and Nasim, I. (2018) 'Comparative evaluation of grape seed and cranberry extracts in preventing enamel erosion: An optical emission spectrometric analysis', Journal of conservative dentistry: JCD, 21(5), pp. 516-520.

Orstavik, D. (1981) 'Antibacterial properties of root canal sealers, cements and pastes', International endodontic journal, 14(2), pp. 125-133. 
Poorni, S., Srinivasan, M. R. and Nivedhitha, M. S. (2019) 'Probiotic strains in caries prevention: A systematic review', Journal of conservative dentistry: JCD, 22(2), pp. 123-128.

Rajakeerthi, R. and Ms, N. (2019) 'Natural Product as the Storage medium for an avulsed tooth - A Systematic Review', Cumhuriyet Dental Journal, 22(2), pp. 249256.

Rajendran, R. et al. (2019) 'Comparative Evaluation of Remineralizing Potential of a Paste Containing Bioactive Glass and a Topical Cream Containing Casein Phosphopeptide-Amorphous Calcium Phosphate: An in Vitro Study', Pesquisa brasileira em odontopediatria e clinica integrada, 19(1), pp. 1-10.

Ramarao, S. and Sathyanarayanan, U. (2019) 'CRA Grid - A preliminary development and calibration of a paper-based objectivization of caries risk assessment in undergraduate dental education', Journal of conservative dentistry: JCD, 22(2), pp. 185-190.

Rechenberg, D.-K., Galicia, J. C. and Peters, 0. A. (2016) 'Biological Markers for Pulpal Inflammation: A Systematic Review’, PloS one, 11(11), p. e0167289.

Samiei, M. et al. (2013) 'Antimicrobial Efficacy of Mineral Trioxide Aggregate with and without Silver Nanoparticles', Iranian endodontic journal, 8(4), pp. 166-170.

Siddique, R. et al. (2019) 'Qualitative and quantitative analysis of precipitate formation following interaction of chlorhexidine with sodium hypochlorite, neem, and tulsi', Journal of conservative dentistry: JCD, 22(1), pp. 40-47.

Siddique, R. and Nivedhitha, M. S. (2019) 'Effectiveness of rotary and reciprocating systems on microbial reduction: A systematic review', Journal of conservative dentistry: JCD, 22(2), pp. 114-122.

Siddique, R., Nivedhitha, M. S. and Jacob, B. (2019) 'Quantitative analysis for detection of toxic elements in various irrigants, their combination (precipitate), and para-chloroaniline: An inductively coupled plasma mass spectrometry study', Journal of conservative dentistry: JCD, 22(4), pp. 344-350.

Silva, E. J. N. L. et al. (2014) 'Evaluation of cytotoxicity, antimicrobial activity and physicochemical properties of a calcium aluminate-based endodontic material', Journal of applied oral science: revista FOB, 22(1), pp. 61-67.

Siqueira, J. F., Jr (2001) 'Aetiology of root canal treatment failure: why well-treated teeth can fail', International endodontic journal. Wiley Online Library, 34(1), pp. 1-10.

Siqueira, J. F., Jr et al. (2002) 'Efficacy of instrumentation techniques and irrigation regimens in reducing the bacterial population within root canals', Journal of endodontia, 28(3), pp. 181-184.

Stowe, T. J. et al. (2004) 'The effects of chlorhexidine gluconate $(0.12 \%)$ on the antimicrobial properties of tooth-colored ProRoot mineral trioxide aggregate', Journal of endodontia, 30(6), pp. 429-431.

Tabassum, S. and Khan, F. R. (2016) 'Failure of endodontic treatment: The usual suspects', European journal of dentistry, 10(1), pp. 144-147.

Tanomaru-Filho, M. et al. (2007) 'In vitro antimicrobial activity of endodontic sealers, MTA-based cements and Portland cement', Journal of oral science, 49(1), pp. 41-45.

Teja, K. V., Ramesh, S. and Priya, V. (2018) 'Regulation of matrix metalloproteinase-3 gene expression in inflammation: A molecular study', Journal of conservative dentistry: JCD, 21(6), pp. 592-596.

Tobias, R. S. (1988) 'Antibacterial properties of dental restorative materials: a review', International endodontic journal, 21(2), pp. 155-160.

Torabinejad, M., Hong, C. U., Pitt Ford, T. R., et al. (1995) 'Antibacterial effects of some root end filling materials', Journal of endodontia, 21(8), pp. 403-406.

Torabinejad, M., Smith, P. W., et al. (1995) 'Comparative investigation of marginal adaptation of mineral trioxide aggregate and other commonly used root-end filling materials', Journal of endodontia, 21(6), pp. 295-299. Torabinejad, M., Hong, C. U., McDonald, F., et al. (1995) 'Physical and chemical properties of a new root-end filling material', Journal of endodontia, 21(7), pp. 349-353.

Torabinejad, M. and Chivian, N. (1999) 'Clinical applications of mineral trioxide aggregate', Journal of Endodontics, pp. 197-205. doi: 10.1016/s00992399(99)80142-3.

Tziafas, D. et al. (2002) 'The dentinogenic effect of mineral trioxide aggregate (MTA) in short-term capping experiments', International endodontic journal, 35(3), pp. 245-254.

Vineet, R. V. and Nayak, M. (2016) 'Enterococcus faecalis: an enigma in root canal infections', International Research Journal of Pharmaceutical and Biosciences, 3(1), pp. 12-21.

Wu, M. K., Kontakiotis, E. G. and Wesselink, P. R. (1998) 'Long-term seal provided by some root-end filling materials', Journal of endodontia, 24(8), pp. 557-560. Zhu, Q. et al. (2000) 'Adhesion of human osteoblasts on root-end filling materials', Journal of endodontia, 26(7), pp. 404-406. 